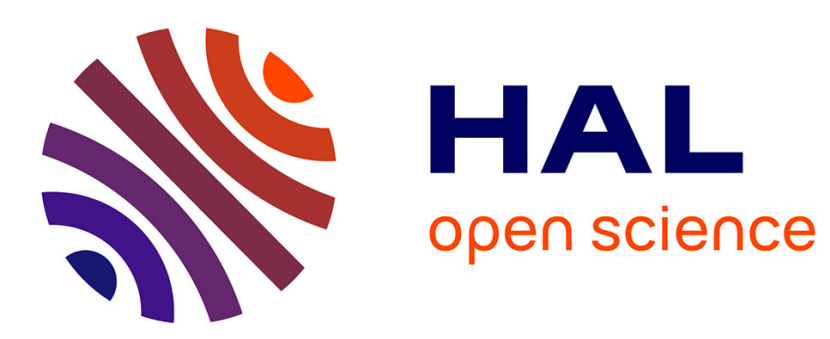

\title{
The Noble-Abel Stiffened-Gas equation of state
}

O Le Métayer, Richard Saurel

\section{To cite this version:}

O Le Métayer, Richard Saurel. The Noble-Abel Stiffened-Gas equation of state. Physics of Fluids, 2016, 28, pp.046102. 10.1063/1.4945981 . hal-01305974

\section{HAL Id: hal-01305974 https://hal.science/hal-01305974}

Submitted on 22 Apr 2016

HAL is a multi-disciplinary open access archive for the deposit and dissemination of scientific research documents, whether they are published or not. The documents may come from teaching and research institutions in France or abroad, or from public or private research centers.
L'archive ouverte pluridisciplinaire HAL, est destinée au dépôt et à la diffusion de documents scientifiques de niveau recherche, publiés ou non, émanant des établissements d'enseignement et de recherche français ou étrangers, des laboratoires publics ou privés. 


\title{
The Noble-Abel Stiffened-Gas Equation of State
}

\author{
O. Le Métayer ${ }^{(1, *)} \&$ R. Saurel ${ }^{(2,3,4)}$ \\ (1) Aix-Marseille University, UMR CNRS 7343, IUSTI, 5 Rue Enrico Fermi, 13453 \\ Marseille Cedex 13, France \\ (2) Aix-Marseille University, Centrale Marseille, UMR CNRS 7340, M2P2, 38 Rue \\ Joliot-Curie, 13451 Marseille, France \\ ${ }^{(3)}$ RS2N, 371 Chemin de Gaumin, 83640 Saint-Zacharie, France \\ (4) University Institute of France \\ ${ }^{(*)}$ corresponding author \\ E-mails : olivier.lemetayer@univ-amu.fr,richard.saurel@univ-amu.fr
}

\begin{abstract}
Hyperbolic two-phase flow models have shown excellent ability for the resolution of a wide range of applications ranging from interfacial flows to fluid mixtures with several velocities. These models account for waves propagation (acoustic and convective) and consist in hyperbolic systems of partial differential equations. In this context, each phase is compressible and needs an appropriate convex equation of state (EOS). The EOS must be simple enough for intensive computations as well as boundary conditions treatment. It must also be accurate, this being challenging with respect to simplicity. In the present approach, each fluid is governed by a novel EOS named 'Noble Abel Stiffened Gas' (NASG), this formulation being a significant improvement of the popular 'Stiffened Gas' (SG) EOS. It is a combination of the so-called 'Noble-Abel' and 'Stiffened Gas' equations of state that adds repulsive effects to the SG formulation. The determination of the various thermodynamic functions and associated coefficients is the aim of this article. We first use thermodynamic considerations to determine the different state functions such as the specific internal energy, enthalpy and entropy. Then we propose to determine the associated coefficients for a liquid in the presence of its vapor. The EOS parameters are determined from experimental saturation curves. Some examples of liquid-vapor fluids are examined and associated parameters are computed with the help of the present method. Comparisons between analytical and experimental saturation curves show very good agreement for wide ranges of temperature for both liquid and vapor.
\end{abstract}




\section{Keywords}

Noble-Abel, Stiffened Gas, two-phase flows, hyperbolic, mass transfer, relaxation

\section{INTRODUCTION}

This article deals with a novel equation of state (EOS) formulation to deal with both compressible liquid and associated vapour. This type of EOS couple (each fluid is governed by its own EOS) is needed in non-equilibrium two-phase compressible flow models. In this context the determination of accurate EOS when evaporation and condensation processes occur is of paramount importance.

Various multiphase flow models considering compressible fluids are present in the literature. The simplest model considers fluids in mechanical and thermal equilibrium and corresponds to a set of 4 partial differential equations [1-3]. To deal with fluid mixtures in mechanical equilibrium but out of thermal equilibrium 5 equations models are available [4-8]. Sevenequation models [9-16] are devoted to flows in total disequilibrium. All these models are unconditionally hyperbolic and are of interest regarding their ability to solve a wide range of physical problems. They allow the resolution of macroscopic interfaces between miscible, immiscible and/or reactive fluids as well as a large range of mixture flows situations.

In these models, the knowledge of each phase EOS is required and their determination is very sensitive when dealing with liquid and vapor phases. Indeed the EOS parameters of both phases are strongly linked each others. Their determination has been the subject of [17] when dealing with 'Stiffened Gas' (SG) EOS. This last EOS summarizes two main molecular effects (agitation and repulsive effects) in a simplified formulation. The determination of the corresponding parameters has also been achieved carefully in [17] with the help of reference data corresponding to experimental saturation results. For example, in Fig.1, the experimental and resulting theoretical (SG EOS) saturation curves are compared for liquid water and steam in the temperature range $[300-500 \mathrm{~K}]$.

In this figure, the saturated vapor pressure $P_{s a t}$, the latent heat of vaporization $L_{v}$, the liquid and vapor saturated specific enthalpies (resp. $h_{l}$ and $h_{g}$ ) and volumes (resp. $v_{l}$ and $v_{g}$ ) are represented versus temperature $T$. All graphs show good agreement between experimental and theoretical curves except in the vicinity of the critical point and for the liquid saturated specific volume. These observations still hold for arbitrary liquid/vapor couples as shown 

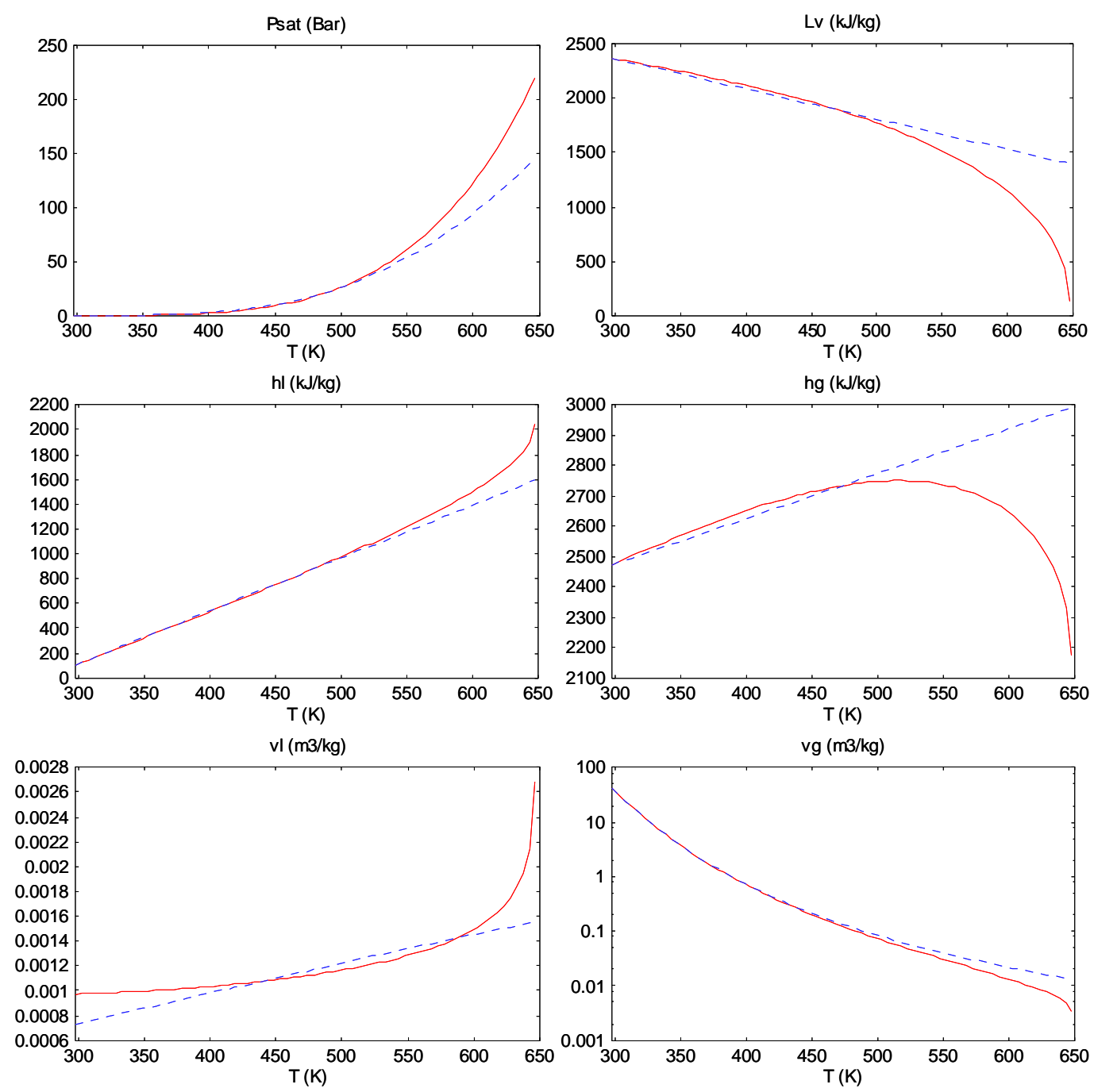

FIG. 1. Experimental (lines) and SG theoretical (dots) saturated variables as functions of the temperature for liquid water and steam. The agreement is excellent for all variables in the temperature range $[300-500 \mathrm{~K}]$ except for the liquid specific volume.

in Fig.2 where liquid saturated specific volume curve is shown for dodecane. Again poor agreement appears for the liquid specific volume.

Nonlinear effects are clearly present near the critical point and the determination of phases thermodynamics near this particular point does not fall in the scope of the present paper. Nevertheless, the problem linked to the liquid specific volume may be fixed by building a new equation of state that accounts for the missing last molecular effect (repulsion) in addition to those already considered (agitation and attraction). The repulsive effect is absent in the SG formulation. Its consideration is the subject of this article that is organized as follows. 


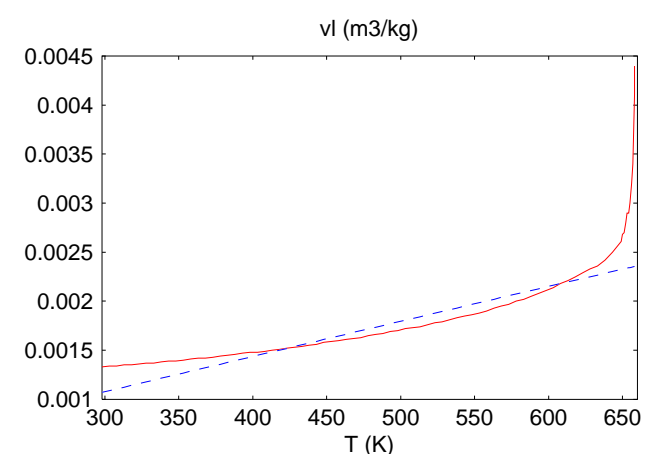

FIG. 2. Experimental (lines) and SG theoretical (dots) saturated specific volume of liquid dodecane.

First general thermodynamic considerations about phase changes are recalled in Section 2. In Section 3, a new EOS named 'Noble Abel Stiffened gas' (NASG) is presented. In Section 4 the determination of the corresponding parameters for both liquid and vapor phases is examined with the help of experimental saturation curves. These parameters are computed for various liquid/vapor couples. Experimental and theoretical curves are systematically compared for each couple. Then in Section 5 a comparison with van der Waals constants is achieved.

\section{THERMODYNAMIC CONSIDERATIONS}

In thermodynamics science, knowledge of two state variables is enough to represent the whole thermodynamic state of a pure fluid. These variables are chosen among the following set of variables or combination of them : specific internal energy, specific entropy, specific volume, pressure and temperature. The equation of state links three of these preceding variables. In the literature, many EOS exist, more or less complex regarding the medium to represent. For evaporation/condensation situations, the EOS must reproduce each fluid behavior (liquid and vapor) as well as the two-phase mixture zone appearing in the phase diagram $(P, v)$ as shown in Fig.3.

In this figure a mixture zone where the liquid and vapor coexist is clearly visible : the saturation dome. This particular zone is bounded by two curves (in liquid and vapor states respectively) merging at the critical point $\left(P_{c}, v_{c}\right)$ and belonging to the critical isotherm $T=T_{c}$. Another important curve is given by a relation linking the pressure and the temperature : the saturated vapor pressure relation $P_{\text {sat }}(T)$. 


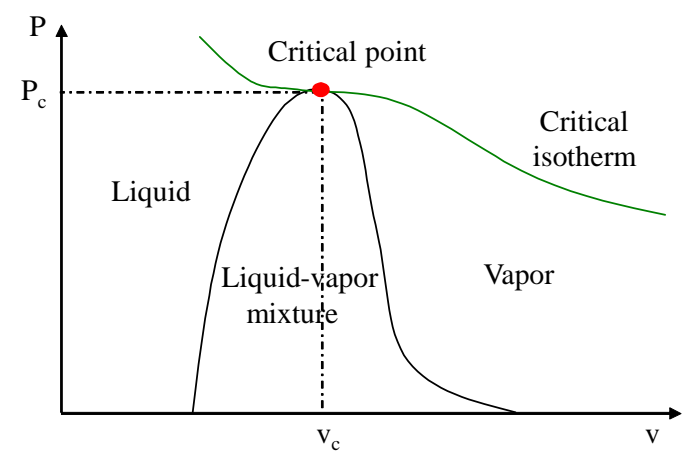

FIG. 3. Schematized liquid/vapor phase diagram.

All the preceding curves are obtained experimentally and correspond to pressure, temperature and Gibbs free energy equilibria between liquid and vapor phases. Many different expressions are available in the literature [18]. For example, [19] proposed the following relation to represent the pressure and temperature dependence at saturation of hydrocarbons,

$$
\ln P_{\text {sat }}=A-\frac{B}{T}+C \ln T+\frac{D P}{T^{2}},
$$

where $P_{\text {sat }}$ and $T$ are respectively the saturated pressure and the associated temperature. The coefficients $A, B, C$ and $D$ are constants obtained experimentally.

Another curve is linked to the latent heat of vaporization $L_{v}(T)$. This one represents the energy needed to evaporate a given liquid quantity at a given temperature. The famous 'Clausius-Clapeyron' relation belongs to the many expressions available in the literature $[18]$,

$$
L_{v}(T)=T\left(v_{g}(T)-v_{l}(T)\right) \frac{d P_{s a t}}{d T}
$$

where $v_{g}(T)$ and $v_{l}(T)$ are respectively the vapor and liquid saturated specific volumes depending on the temperature $T$.

It is clear that all saturations curves are representative of the liquid/vapor couple under consideration. The different EOS aimed to describe the pure fluid behavior are thus strongly dependent on these saturation curves. The strategy adopted in the paper thus needs the determination of each phase EOS and the determination of mass transfer kinetics when evaporation or condensation occur. This last can be modelled as instantaneous [3, 7] or finite rate [21]. The building of such EOS couples is the aim of the present work. The EOS under investigation in this paper is a combination of the so-called 'Noble-Abel' and 
'Stiffened Gas' EOS. Its simple analytical form allows explicit mathematical calculations of important flow relations which are at the centre of theoretical analysis (acoustic properties, invariants, Riemann problems, ...) while retaining with high accuracy the main physical properties of the matter (agitation, attractive and repulsive molecular effects). This EOS is described hereafter.

\section{THE 'NOBLE-ABEL STIFFENED GAS' (NASG) EQUATION OF STATE}

The NASG caloric equation of state $P=P(v, e)$ reads,

$$
P=(\gamma-1) \frac{(e-q)}{(v-b)}-\gamma P_{\infty}
$$

where $P, v, e$ and $q$ are respectively the pressure, the specific volume, the specific internal energy and the heat bond of the corresponding phase. Parameters $\gamma, P_{\infty}, q$ and $b$ are constant coefficients characteristic of the thermodynamic properties of the fluid. Among them the coefficient $b$ represents the covolume of the fluid. This equation of state is a combination of the 'Stiffened Gas' EOS described in [22-24] and the so-called 'Noble-Abel' EOS [25]. The term $(\gamma-1)(e-q)$ represents thermal agitation while $(v-b)$ represents repulsive short distance effects linked to molecular motion in gases, liquids and solids. The term $\gamma P_{\infty}$ corresponds to attractive effects leading to matter cohesion in liquid and solid states [26]. In many applications, knowledge of the temperature is needed. It is thus necessary to determine the thermal equations of state $T=T(v, e)$ or $T=T(v, P)$ that are not yet available at this stage. In order to determine these ones, some fundamental relations are needed : the Maxwell rules.

\section{A. Maxwell rules}

These relations are obtained by equating the second derivatives of thermodynamic potentials such as the Helmholtz free energy $F=e-T s$ and the Gibbs free energy $G=h-T s$ where $h=e+P v$ is the specific enthalpy. For more details about the determination of such relations, we refer for example to [27].

Maxwell rules read,

$$
\left(\frac{\partial e}{\partial v}\right)_{T}=T\left(\frac{\partial P}{\partial T}\right)_{v}-P,
$$




$$
\left(\frac{\partial s}{\partial P}\right)_{T}=-\left(\frac{\partial v}{\partial T}\right)_{P} .
$$

\section{B. Determination of the different NASG EOS}

In this section the determination of the thermal EOS $P(v, T)$ is in focus. This EOS has to fulfill the preceding Maxwell rules. When determined, other thermodynamic functions are deduced.

By inverting the relation (3), we get,

$$
e(v, T)=\frac{P(v, T)+\gamma P_{\infty}}{(\gamma-1)}(v-b)+q,
$$

where $P(v, T)$ is unknown at this stage.

The following partial derivatives are deduced from the relation (6),

$$
\begin{gathered}
\left(\frac{\partial e}{\partial T}\right)_{v}=\frac{(v-b)}{(\gamma-1)}\left(\frac{\partial P}{\partial T}\right)_{v}, \\
\left(\frac{\partial e}{\partial v}\right)_{T}=\frac{(v-b)}{(\gamma-1)}\left(\frac{\partial P}{\partial v}\right)_{T}+\frac{P+\gamma P_{\infty}}{(\gamma-1)} .
\end{gathered}
$$

The Maxwell rule (4) and the last relation (8) are now combined leading to,

$$
\left(\frac{\partial P}{\partial v}\right)_{T}=\frac{(\gamma-1) T}{(v-b)}\left(\frac{\partial P}{\partial T}\right)_{v}-\frac{\gamma\left(P+P_{\infty}\right)}{(v-b)} .
$$

Besides $C_{v}=\left(\frac{\partial e}{\partial T}\right)_{v}$ where $C_{v}$ is the heat capacity at constant volume is now used. This parameter has a constant value for each phase in the NASG approximation. With the help of relation (7), we get,

$$
\left(\frac{\partial P}{\partial T}\right)_{v}=\frac{(\gamma-1) C_{v}}{(v-b)}
$$

The preceding relation is integrated over the temperature $T$,

$$
P(v, T)=\frac{(\gamma-1) C_{v} T}{(v-b)}+K(v)
$$

where $K(v)$ is a function of the specific volume $v$.

The expression (11) is derived over $v$ at constant temperature yielding,

$$
\left(\frac{\partial P}{\partial v}\right)_{T}=-\frac{(\gamma-1) C_{v} T}{(v-b)^{2}}+\frac{d K}{d v} .
$$


Now expressions (10) and (11) are embedded in relation (9),

$$
\left(\frac{\partial P}{\partial v}\right)_{T}=-\frac{(\gamma-1) C_{v} T}{(v-b)^{2}}-\frac{\gamma}{(v-b)}\left(K(v)+P_{\infty}\right) .
$$

The equality between relations (12) and (13) leads to the following first order differential equation,

$$
\frac{d K}{d v}+\frac{\gamma}{(v-b)}\left(K(v)+P_{\infty}\right)=0
$$

The solution of (14) is given by,

$$
K(v)=\frac{C}{(v-b)^{\gamma}}-P_{\infty}
$$

where $C$ is a constant to be determined.

As a consequence the law $P(v, T)$ reads,

$$
P(v, T)=\frac{(\gamma-1) C_{v} T}{(v-b)}+\frac{C}{(v-b)^{\gamma}}-P_{\infty}
$$

The constant $C$ is computed so that the preceding relation (16) is fulfilled at a given reference state $\left(P_{0}, T_{0}, v_{0}\right)$,

$$
P\left(v_{0}, T_{0}\right)=\frac{(\gamma-1) C_{v} T_{0}}{\left(v_{0}-b\right)}+\frac{C}{\left(v_{0}-b\right)^{\gamma}}-P_{\infty}=P_{0}
$$

The corresponding expression of $C$ thus reads,

$$
C=\left(v_{0}-b\right)^{\gamma}\left(P_{0}+P_{\infty}-\frac{(\gamma-1) C_{v} T_{0}}{\left(v_{0}-b\right)}\right) .
$$

A simple analysis of this relation may lead to a negative value for the constant $C$. In this case the isothermal curves are non-monotonic. Indeed for a single value of the pressure and the temperature, more than one value of the specific volume may be obtained, such behavior being unacceptable. Furthermore the square sound speed may become negative. In order to avoid such unphysical behavior linked to the term $\frac{C}{(v-b)^{\gamma}}$ in the law $P(v, T)$ (16), another particular solution of (14) is preferred by imposing $C=0$. The corresponding solution reads,

$$
P(v, T)=\frac{(\gamma-1) C_{v} T}{(v-b)}-P_{\infty}
$$

Then the reference state is not used explicitly anymore. Nevertheless as shown later the determination of the parameters for each phase will be based on some reference states. The expression of the law $P(v, T)$ being available at this stage, the other thermodynamic 
variables may be obtained from the knowledge of the two independent variables $P$ and $T$. The relation (19) is inverted and reads,

$$
v(P, T)=\frac{(\gamma-1) C_{v} T}{P+P_{\infty}}+b .
$$

From the expressions (6) and (20) we get,

$$
e(P, T)=\frac{P+\gamma P_{\infty}}{\gamma-1}(v(P, T)-b)+q=\frac{P+\gamma P_{\infty}}{P+P_{\infty}} C_{v} T+q .
$$

Then the expression of the specific enthalpy is readily obtained,

$$
h(P, T)=e(P, T)+P v(P, T)=\gamma C_{v} T+b P+q .
$$

The constant $q$ is computed so that the specific internal energy is equal to $e_{0}$ at a reference state $\left(P_{0}, T_{0}\right)$,

$$
q=e_{0}-\frac{P_{0}+\gamma P_{\infty}}{P_{0}+P_{\infty}} C_{v} T_{0}
$$

As $h_{0}=e_{0}+P_{0} v_{0}=e_{0}+P_{0}\left(\frac{(\gamma-1) C_{v} T_{0}}{P_{0}+P_{\infty}}+b\right)$ we still have,

$$
q=h_{0}-\gamma C_{v} T_{0}-b P_{0} .
$$

It is important to note that the specific enthalpy $h$ depends on the temperature $T$ and the pressure $P$. In the 'Stiffened Gas' approximation this one only depends on the temperature. Another parameter under consideration in our study is the heat capacity at constant pressure defined as $C_{P}=\left(\frac{\partial h}{\partial T}\right)_{P}$. For the NASG EOS the expression of this parameter is deduced from relation $(22)$,

$$
C_{P}=\gamma C_{v}
$$

In order to determine the specific entropy $s$ the second Maxwell rule (5) is now considered. Taking the derivative of expression (20) the second Maxwell rule becomes,

$$
\left(\frac{\partial s}{\partial P}\right)_{T}=-\left(\frac{\partial v}{\partial T}\right)_{P}=-\frac{(\gamma-1) C_{v}}{P+P_{\infty}} .
$$

The integration of (26) is immediate,

$$
s(P, T)=-(\gamma-1) C_{v} \ln \left(P+P_{\infty}\right)+K(T),
$$

where $K(T)$ is a function of the temperature. The expression of the Gibbs free energy $G=h-T s$ is now considered through temperature derivative at constant pressure,

$$
\left(\frac{\partial G}{\partial T}\right)_{P}=\left(\frac{\partial h}{\partial T}\right)_{P}-s-T\left(\frac{\partial s}{\partial T}\right)_{P} .
$$


Moreover combining relations $(22)$ and $\left(\frac{\partial G}{\partial T}\right)_{P}=-s$ leads to,

$$
\left(\frac{\partial s}{\partial T}\right)_{P}=\frac{1}{T}\left(\frac{\partial h}{\partial T}\right)_{P}=\frac{\gamma C_{v}}{T}
$$

By taking the temperature derivative of (27) at constant pressure and using the preceding relation (29), the function $K(T)$ reads,

$$
K(T)=\gamma C_{v} \ln T+q^{\prime}
$$

where $q^{\prime}$ is a constant. The general expression of the law $s(P, T)$ thus becomes,

$$
s(P, T)=C_{v} \ln \frac{T^{\gamma}}{\left(P+P_{\infty}\right)^{\gamma-1}}+q^{\prime} .
$$

Now the expression of the Gibbs free energy $G$ is readily obtained,

$$
G(P, T)=h(P, T)-T s(P, T)=\left(\gamma C_{v}-q^{\prime}\right) T-C_{v} T \ln \frac{T^{\gamma}}{\left(P+P_{\infty}\right)^{\gamma-1}}+b P+q
$$

Additional thermodynamic coefficients may be needed. In compressible fluid mechanics knowledge of the speed of sound is fundamental. With the NASG formulation this one reads,

$$
c^{2}=-v^{2}\left(\frac{\partial P}{\partial v}\right)_{s}=\frac{\gamma v^{2}\left(P+P_{\infty}\right)}{(v-b)} .
$$

Furthermore convexity of the NASG EOS is examined in Appendix.

\section{Summary of the different NASG state functions}

The different state functions of common use are,

$$
\begin{gathered}
e(P, v)=\frac{P+\gamma P_{\infty}}{\gamma-1}(v-b)+q, \\
v(P, T)=\frac{(\gamma-1) C_{v} T}{P+P_{\infty}}+b, \\
h(P, T)=\gamma C_{v} T+b P+q, \\
G(P, T)=\left(\gamma C_{v}-q^{\prime}\right) T-C_{v} T \ln \frac{T^{\gamma}}{\left(P+P_{\infty}\right)^{\gamma-1}}+b P+q .
\end{gathered}
$$

The parameters that have to be determined are the followings : $\gamma, P_{\infty}, C_{v}, b, q$ and $q^{\prime}$. Thus for a liquid/vapor couple twelve constants are needed. 


\section{DETERMINATION OF THE NASG PARAMETERS}

\section{A. Methodology}

Determination of the various parameters is based on experimental data denoted by subscript exp in the paper. Considering a liquid and its vapor denoted by subscripts $l$ and $g$ respectively the experimental curves under consideration are the so-called saturation curves. The experimental points from these curves are obtained by varying the pressure or the temperature of a liquid/vapor mixture at thermodynamic equilibrium (pressure, temperature and Gibbs free energy equilibrium). Each value of the temperature leads to a unique value of the pressure (named saturated vapor pressure) and a unique value of the Gibbs free energy. At each equilibrium state each phase has its own specific volume and specific enthalpy. All saturated thermodynamic states are denoted in the rest of the paper by subscript sat. Then the available experimental saturation curves in analytical or tabulated forms are : $P_{\text {sat,exp }}(T), h_{l, \exp }(T), h_{g, \exp }(T), v_{l, \exp }(T), v_{g, \exp }(T)$. The latent heat of vaporization is given by the formula,

$$
L_{v, \exp }(T)=h_{g, \exp }(T)-h_{l, \exp }(T)
$$

The corresponding theoretical expressions of the saturated vapor pressure and the latent heat of vaporization with the NASG formulation are now examined. In the rest of the paper, the liquid and vapor phases are represented by subscripts $l$ and $g$ respectively.

From the relation (37) the Gibbs free energy for both phases reads,

$$
\begin{gathered}
G_{l}(P, T)=\left(\gamma_{l} C_{v, l}-q_{l}^{\prime}\right) T-C_{v, l} T \ln \frac{T^{\gamma_{l}}}{\left(P+P_{\infty, l}\right)^{\gamma_{l}-1}}+b_{l} P+q_{l}, \\
G_{g}(P, T)=\left(\gamma_{g} C_{v, g}-q_{g}^{\prime}\right) T-C_{v, g} T \ln \frac{T^{\gamma_{g}}}{\left(P+P_{\infty, g}\right)^{\gamma_{g}-1}}+b_{g} P+q_{g} .
\end{gathered}
$$

Equality of the two previous relations (39) and (40) leads to the following expression linking the pressure and the temperature,

$$
\ln \left(P+P_{\infty, g}\right)=A+\frac{(B+E P)}{T}+C \ln T+D \ln \left(P+P_{\infty, l}\right)
$$

where the coefficients are given by,

$$
A=\frac{C_{P, l}-C_{P, g}+q_{g}^{\prime}-q_{l}^{\prime}}{C_{P, g}-C_{v, g}}, \quad B=\frac{q_{l}-q_{g}}{C_{P, g}-C_{v, g}},
$$




$$
\begin{gathered}
C=\frac{C_{P, g}-C_{P, l}}{C_{P, g}-C_{v, g}}, \quad D=\frac{C_{P, l}-C_{v, l}}{C_{P, g}-C_{v, g}}, \\
E=\frac{b_{l}-b_{g}}{C_{P, g}-C_{v, g}} .
\end{gathered}
$$

Relation (41) provides a unique value of the pressure for a given temperature. Actually this relation implicitly represents the theoretical saturated vapor pressure as a function of temperature : $P_{\text {sat }}(T)$. It is worth to mention that this theoretical expression is quite close to experimental curve fittings such as (1).

The theoretical expression of the latent heat of vaporization reads,

$$
L_{v}(T)=h_{g}(T)-h_{l}(T)
$$

where the saturated specific enthalpies of both phases read,

$$
\begin{gathered}
h_{g}(T)=\gamma_{g} C_{v, g} T+b_{g} P_{s a t}(T)+q_{g}, \\
h_{l}(T)=\gamma_{l} C_{v, l} T+b_{l} P_{s a t}(T)+q_{l} .
\end{gathered}
$$

The saturated specific volumes of both phases also read,

$$
\begin{gathered}
v_{g}(T)=\frac{\left(\gamma_{g}-1\right) C_{v, g} T}{P_{s a t}(T)+P_{\infty, g}}+b_{g}, \\
v_{l}(T)=\frac{\left(\gamma_{l}-1\right) C_{v, l} T}{P_{s a t}(T)+P_{\infty, l}}+b_{l} .
\end{gathered}
$$

The coefficients $\gamma, C_{v}, P_{\infty}, q, b$ and $q^{\prime}$ must be determined for each phase in order that the preceding theoretical relations match as much as possible the experimental saturation data. As described in [17] the vapor phase may obey the ideal gas EOS. Indeed the theoretical curves obtained with the ideal gas EOS are close to the experimental ones. This remark leads to the following trivial relations : $b_{g}=0 \mathrm{~m}^{3} / \mathrm{kg}$ and $P_{\infty, g}=0 \mathrm{~Pa}$. For the vapor phase the coefficients that must be determined are consequently : $\gamma_{g}, C_{v, g}, q_{g}$ and $q_{g}^{\prime}$. In order to determine the preceding coefficients, a temperature range is given and the number of experimental points inside this range is denoted in the following by $N$.

First the relation under consideration is,

$$
h_{g}(T)=\gamma_{g} C_{v, g} T+q_{g}=C_{P, g} T+q_{g}
$$




\section{Determination of $C_{P, g}$ and $q_{g}$ for the vapor phase}

At this stage, the experimental points $\left(T_{\text {exp }, i}, i=1 . . N\right)$ and $\left(h_{g, e x p, i}, i=1 . . N\right)$ are considered. The least squares method is used to determine the coefficients $C_{P, g}$ and $q_{g}$ in relation (47). The function to minimize reads,

$$
f\left(C_{P, g}, q_{g}\right)=\sum_{i=1}^{N}\left(h_{g, \exp , i}-C_{P, g} T_{\exp , i}-q_{g}\right)^{2} .
$$

The system to be solved is thus the following,

$$
\left\{\begin{array}{l}
\sum_{i=1}^{N}\left(h_{g, e x p, i}-C_{P, g} T_{e x p, i}-q_{g}\right) T_{e x p, i}=0 \\
\sum_{i=1}^{N}\left(h_{g, e x p, i}-C_{P, g} T_{e x p, i}-q_{g}\right)=0
\end{array} .\right.
$$

The solutions of (49) correspond to the coefficients $C_{P, g}$ and $q_{g}$,

$$
\begin{gathered}
C_{P, g}=\frac{\sum_{i=1}^{N} T_{e x p, i}\left(h_{g, e x p, i}-\bar{h}_{g, e x p}\right)}{\sum_{i=1}^{N} T_{e x p, i}\left(T_{e x p, i}-\bar{T}_{e x p}\right)} \\
q_{g}=\bar{h}_{g, \text { exp }}-C_{P, g} \bar{T}_{e x p}
\end{gathered}
$$

where $\bar{h}_{g, \exp }=\frac{1}{N} \sum_{i=1}^{N} h_{g, e x p, i}$ and $\bar{T}_{\text {exp }}=\frac{1}{N} \sum_{i=1}^{N} T_{e x p, i}$ are respectively the vapor specific enthalpy and the temperature averages inside the considered temperature range.

The average coefficients $C_{P, g}$ and $q_{g}$ are now determined and are only valid inside the corresponding temperature range.

Now the relation under consideration is,

$$
v_{g}(T)=\frac{\left(\gamma_{g}-1\right) C_{v, g} T}{P_{s a t}(T)}=\frac{\left(C_{P, g}-C_{v, g}\right) T}{P_{s a t}(T)}
$$

\section{Determination of $C_{P, g}-C_{v, g}$ for the vapor phase}

The experimental points $\left(T_{\text {exp }, i}, i=1 . . N\right)$ and $\left(P_{\exp , i}, i=1 . . N\right)$ corresponding to the same preceding temperature range are considered. The least squares method is again used to determine the only coefficient $C_{P, g}-C_{v, g}$ appearing in relation (52). The function to minimize reads,

$$
f\left(C_{P, g}-C_{v, g}\right)=\sum_{i=1}^{N}\left(v_{g, e x p, i}-\frac{\left(C_{P, g}-C_{v, g}\right) T_{e x p, i}}{P_{e x p, i}}\right)^{2}
$$


The system to solve reduces to the single following relation,

$$
\sum_{i=1}^{N}\left(v_{g, e x p, i}-\frac{\left(C_{P, g}-C_{v, g}\right) T_{e x p, i}}{P_{\text {exp }, i}}\right) \frac{T_{e x p, i}}{P_{\text {exp }, i}}=0 .
$$

The solution of (54) is given by,

$$
C_{P, g}-C_{v, g}=\frac{\sum_{i=1}^{N} v_{g, e x p, i} \frac{T_{e x p, i}}{P_{e x p, i}}}{\sum_{i=1}^{N}\left(\frac{T_{e x p, i}}{P_{e x p, i}}\right)^{2}}
$$

Combining relations (50) and (55) allows the determination of the coefficients $C_{v, g}$ and $\gamma_{g}=\frac{C_{P, g}}{C_{v, g}}$. The parameter $q_{g}^{\prime}$ will be determined further when considering the theoretical vapor pressure relation.

Regarding the liquid phase the coefficients that must be determined are $: \gamma_{l}, C_{v, l}, P_{\infty, l}, q_{l}$, $b_{l}$ and $q_{l}^{\prime}$. The theoretical relations (44) and (46) of the liquid phase read,

$$
\begin{gathered}
h_{l}(T)=C_{P, l} T+b_{l} P_{s a t}(T)+q_{l}, \\
v_{l}(T)=\frac{\left(C_{P, l}-C_{v, l}\right) T}{P_{s a t}(T)+P_{\infty, l}}+b_{l} .
\end{gathered}
$$

\section{Determination of $C_{P, l}$ and $q_{l}$ for the liquid phase}

The experimental points $\left(T_{e x p, i}, i=1 . . N\right),\left(P_{e x p, i}, i=1 . . N\right)$ and $\left(h_{l, e x p, i}, i=1 . . N\right)$ are now considered. When applying the least squares method in relation (56) aimed to determine the coefficients $C_{P, l}$ and $q_{l}$, the function to minimize reads,

$$
f\left(C_{P, l}, q_{l}\right)=\sum_{i=1}^{N}\left(h_{l, \exp , i}-C_{P, l} T_{\text {exp }, i}-b_{l} P_{\text {exp }, i}-q_{l}\right)^{2} .
$$

The resulting system to solve reads,

$$
\left\{\begin{array}{l}
\sum_{i=1}^{N}\left(h_{l, \exp , i}-C_{P, l} T_{\exp , i}-b_{l} P_{\exp , i}-q_{l}\right) T_{\exp , i}=0 \\
\sum_{i=1}^{N}\left(h_{l, \exp , i}-C_{P, l} T_{\exp , i}-b_{l} P_{\exp , i}-q_{l}\right)=0
\end{array} .\right.
$$

The solution of system (59) is obtained as,

$$
C_{P, l}=\frac{\sum_{i=1}^{N} T_{e x p, i}\left(h_{l, e x p, i}-\bar{h}_{l, e x p}\right)-b_{l} \sum_{i=1}^{N} T_{e x p, i}\left(P_{e x p, i}-\bar{P}_{e x p}\right)}{\sum_{i=1}^{N} T_{e x p, i}\left(T_{e x p, i}-\bar{T}_{e x p}\right)}
$$




$$
q_{l}=\bar{h}_{l, e x p}-C_{P, l} \bar{T}_{e x p}-b_{l} \bar{P}_{e x p},
$$

where $\bar{h}_{l, e x p}=\frac{1}{N} \sum_{i=1}^{N} h_{l, e x p, i}, \bar{T}_{\text {exp }}=\frac{1}{N} \sum_{i=1}^{N} T_{e x p, i}$ and $\bar{P}_{\text {exp }}=\frac{1}{N} \sum_{i=1}^{N} P_{e x p, i}$ are respectively the liquid specific enthalpy, the temperature and the pressure averages inside the corresponding range.

In relations (60) and (61) a dependence of the parameters $C_{P, l}$ and $q_{l}$ on the coefficient $b_{l}$ appears. Once $b_{l}$ is computed the coefficients $C_{P, l}$ and $q_{l}$ are deduced.

\section{Determination of $C_{P, l}-C_{v, l}$ and $b_{l}$ for the liquid phase}

The experimental points $\left(T_{\exp , i}, i=1 . . N\right),\left(P_{\exp , i}, i=1 . . N\right)$ and $\left(v_{l, \exp , i}, i=1 . . N\right)$ are considered. The coefficients $C_{P, l}-C_{v, l}$ and $b_{l}$ are determined applying the least squares method in relation (57). Here the function to minimize is given by,

$$
f\left(C_{P, l}-C_{v, l}, b_{l}\right)=\sum_{i=1}^{N}\left(v_{l, e x p, i}-\frac{\left(C_{P, l}-C_{v, l}\right) T_{e x p, i}}{P_{e x p, i}+P_{\infty, l}}-b_{l}\right)^{2} .
$$

The system to solve is now given by,

$$
\left\{\begin{array}{l}
\sum_{i=1}^{N}\left(v_{l, e x p, i}-\frac{\left(C_{P, l}-C_{v, l}\right) T_{e x p, i}}{P_{e x p, i}+P_{\infty, l}}-b_{l}\right) \frac{T_{\text {exp }, i}}{P_{e x p, i}+P_{\infty, l}}=0 \\
\sum_{i=1}^{N}\left(v_{l, e x p, i}-\frac{\left(C_{P, l}-C_{v, l}\right) T_{e x p, i}}{P_{\text {exp }, i}+P_{\infty, l}}-b_{l}\right)=0
\end{array} .\right.
$$

Solutions of system (63) reads,

$$
\begin{gathered}
C_{P, l}-C_{v, l}=\frac{\sum_{i=1}^{N} \frac{T_{\text {exp }, i}}{P_{\text {exp }, i}+P_{\infty, l}}\left(v_{l, e x p, i}-\bar{v}_{l, e x p}\right)}{\sum_{i=1}^{N} \frac{T_{\text {exp }, i}}{P_{\text {exp }, i}+P_{\infty, l}}\left(\frac{T_{\text {exp }, i}}{P_{\text {exp }, i}+P_{\infty, l}}-\left(\frac{T}{P}\right)_{e x p}\right)} \\
b_{l}=\bar{v}_{l, e x p}-\left(C_{P, l}-C_{v, l}\right)\left(\frac{T}{P}\right)_{\text {exp }}
\end{gathered}
$$

where $\bar{v}_{l, \exp }=\frac{1}{N} \sum_{i=1}^{N} v_{l, e x p, i}$ is the liquid specific volume average inside the temperature range and $\left(\overline{\frac{T}{P}}\right)_{\text {exp }}=\frac{1}{N} \sum_{i=1}^{N} \frac{T_{e x p, i}}{P_{e x p, i}+P_{\infty, l}}$.

A dependence of the parameters $C_{P, l}-C_{v, l}$ and $b_{l}$ on the coefficient $P_{\infty, l}$ appears. Once this coefficient is known the parameters $C_{P, l}-C_{v, l}$ and $b_{l}$ are fully determined thanks to 
relations (64) and (65) and so are the parameters $C_{P, l}$ and $q_{l}$ with the help of relations (60) and (61). Hence the four previous parameters only depend on the variable $P_{\infty, l}$ that has to be determined.

\section{Determination of $P_{\infty, l}$ for the liquid phase}

Knowledge of a liquid reference state is now needed : $c_{0}, P_{0}$ and $\rho_{0}$. The theoretical relation linking these preceding values corresponds to relation (33) and reads,

$$
c_{0}^{2}=\frac{C_{P, l}\left(P_{0}+P_{\infty, l}\right)}{C_{v, l} \rho_{0}\left(1-b_{l} \rho_{0}\right)}
$$

where $C_{P, l}, C_{v, l}, P_{\infty, l}$ and $b_{l}$ are still unknowns. As previously mentioned all parameters in relation (66) only depend on the variable $P_{\infty, l}$.

The relation (66) may be written under the following form,

$$
P_{0}+P_{\infty, l}-\left(1-\frac{\left(C_{P, l}-C_{v, l}\right)}{C_{P, l}}\right) \rho_{0} c_{0}^{2}\left(1-b_{l} \rho_{0}\right)=0 .
$$

As the parameters $C_{P, l}-C_{v, l}, C_{P, l}$ and $b_{l}$ only depend on $P_{\infty, l}$ the relation (67) consists in a function depending on $P_{\infty, l}$ only,

$$
f\left(P_{\infty, l}\right)=P_{0}+P_{\infty, l}-\left(1-\frac{\left(C_{P, l}-C_{v, l}\right)}{C_{P, l}}\right) \rho_{0} c_{0}^{2}\left(1-b_{l} \rho_{0}\right)=0 .
$$

The solution of (68) is found by an arbitrary numerical method (Newton-Raphson method for example).

\section{Determination of the entropy constants $q_{l}^{\prime}$ and $q_{g}^{\prime}$}

The parameters that are still unknown at this stage are the entropy constants : $q_{l}^{\prime}$ and $q_{g}^{\prime}$. They are determined with the help of the experimental vapor pressure as a function of temperature. The theoretical relation is given by relation (41),

$$
\ln P=A+\frac{(B+E P)}{T}+C \ln T+D \ln \left(P+P_{\infty, l}\right),
$$

where the coefficients $B, C, D$ and $E$ are fully determined by the previous methodology. The only unknown corresponds to the coefficient $A=\frac{C_{P, l}-C_{P, g}+q_{g}^{\prime}-q_{l}^{\prime}}{C_{P, g}-C_{v, g}}$ where $q_{l}^{\prime}$ and $q_{g}^{\prime}$ are present. As these last coefficients are constant reference energies, the adopted convention 
is the following : $q_{l}^{\prime}=0 \mathrm{~J} /(\mathrm{kg} \cdot \mathrm{K})$.

Here the experimental points $\left(T_{\text {exp }, i}, i=1 . . N\right)$ and $\left(P_{\text {exp }, i}, i=1 . . N\right)$ are considered. The least squares method is once again used to determine the coefficient $A$ in relation (69).

The function to minimize reads,

$$
f(A)=\sum_{i=1}^{N}\left(\ln \left(P_{\text {exp }, i}\right)-A-\frac{\left(B+E P_{\text {exp }, i}\right)}{T_{\text {exp }, i}}-C \ln \left(T_{\text {exp }, i}\right)-D \ln \left(P_{\text {exp }, i}+P_{\infty, l}\right)\right)^{2} .
$$

The equation to be solved is given by,

$$
\sum_{i=1}^{N}\left(\ln \left(P_{e x p, i}\right)-A-\frac{\left(B+E P_{e x p, i}\right)}{T_{e x p, i}}-C \ln \left(T_{e x p, i}\right)-D \ln \left(P_{e x p, i}+P_{\infty, l}\right)\right)=0 .
$$

Solution of (71) reads,

$$
A=\frac{1}{N} \sum_{i=1}^{N}\left(\ln \left(P_{\text {exp }, i}\right)-\frac{\left(B+E P_{\text {exp }, i}\right)}{T_{\text {exp }, i}}-C \ln \left(T_{\text {exp }, i}\right)-D \ln \left(P_{\text {exp }, i}+P_{\infty, l}\right)\right) .
$$

The parameter $q_{g}^{\prime}$ is thus readily obtained.

The preceding methodology is now directly applied to dodecane parameters determination. 


\section{B. NASG coefficients for liquid/vapor dodecane}

The experimental data for dodecane are given in [20]. The reference state for the liquid phase is : $\rho_{0}=589.73 \mathrm{~kg} / \mathrm{m}^{3}, P_{0}=1.128 \mathrm{bar}, c_{0}=620.4 \mathrm{~m} / \mathrm{s}$.

For $T \in[300-500 \mathrm{~K}]$, the corresponding values of the NASG parameters of both phases are given in the Table I.

\begin{tabular}{|l|c|c|}
\hline Coefficients & Liquid phase & Vapor phase \\
\hline$C_{P}(\mathrm{~J} / \mathrm{kg} / \mathrm{K})$ & 2608 & 2063 \\
\hline$C_{v}(\mathrm{~J} / \mathrm{kg} / \mathrm{K})$ & 2393 & 2016 \\
\hline$\gamma$ & 1.09 & 1.02 \\
\hline$P_{\infty}(\mathrm{Pa})$ & $1159 \times 10^{5}$ & 0 \\
\hline$b\left(\mathrm{~m}^{3} / \mathrm{kg}\right)$ & $7.51 \times 10^{-4}$ & 0 \\
\hline$q(\mathrm{~J} / \mathrm{kg})$ & -794696 & -268561 \\
\hline$q^{\prime}(\mathrm{J} /(\mathrm{kg} . \mathrm{K}))$ & 0 & 471 \\
\hline
\end{tabular}

TABLE I. NASG coefficients for dodecane in the temperature range [300 - 500 K].

For comparison the SG parameters obtained with the method given in [17] are given in the Table II for the same temperature range.

\begin{tabular}{|l|c|c|}
\hline Coefficients & Liquid phase & Vapor phase \\
\hline$C_{P}(\mathrm{~J} / \mathrm{kg} / \mathrm{K})$ & 2608 & 2063 \\
\hline$C_{v}(\mathrm{~J} / \mathrm{kg} / \mathrm{K})$ & 1974 & 2016 \\
\hline$\gamma$ & 1.32 & 1.02 \\
\hline$P_{\infty}(\mathrm{Pa})$ & $1717 \times 10^{5}$ & 0 \\
\hline$q(\mathrm{~J} / \mathrm{kg})$ & -794826 & -268561 \\
\hline$q^{\prime}(\mathrm{J} /(\mathrm{kg} . \mathrm{K}))$ & 0 & -7569 \\
\hline
\end{tabular}

TABLE II. SG coefficients for dodecane in the temperature range $[300-500 \mathrm{~K}]$.

The experimental and theoretical saturation curves are compared in Fig.4. The theoretical saturation curves are represented for both NASG and SG EOS with the coefficients of Tables I and II. 

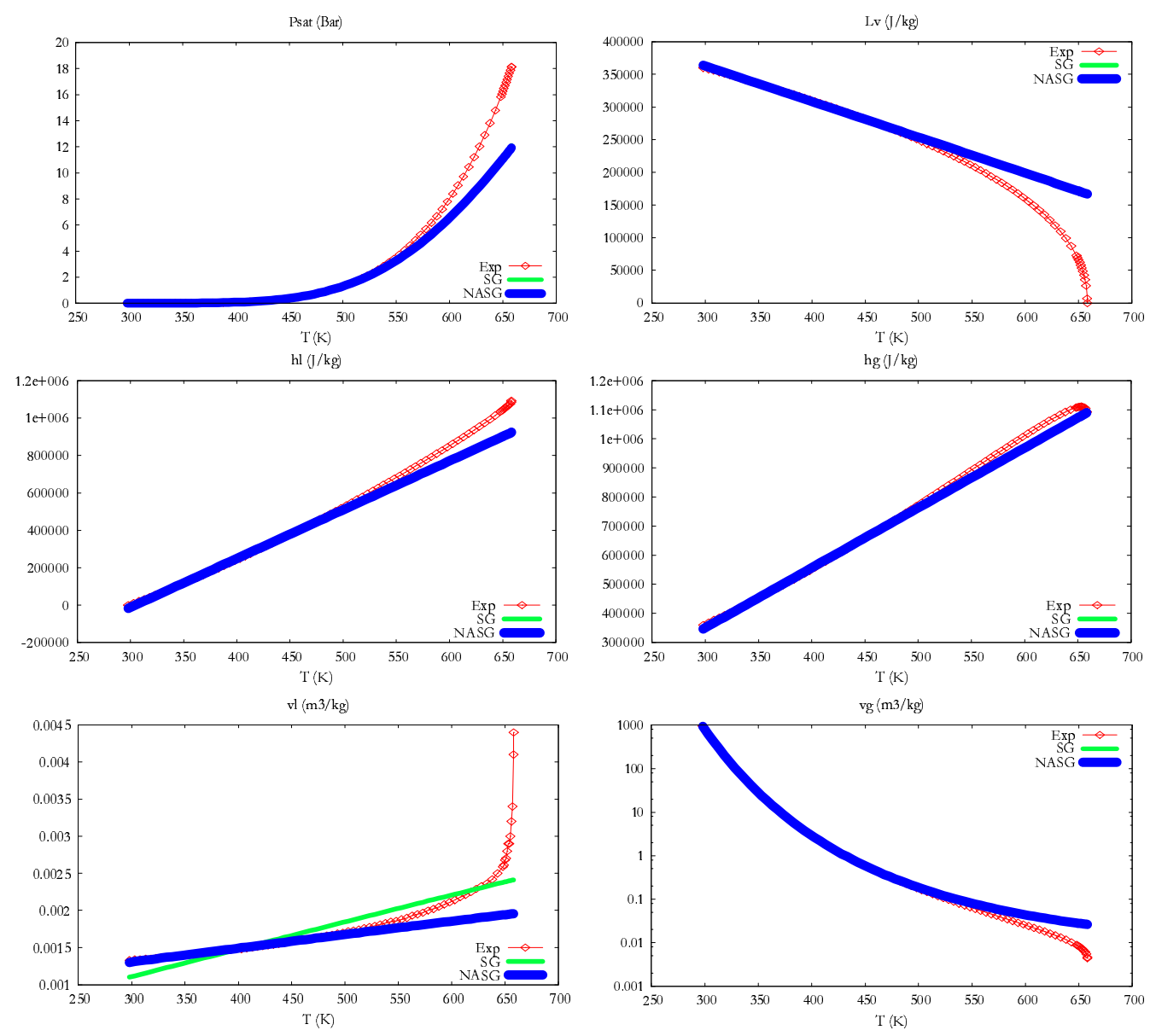

FIG. 4. Comparison between experimental (symbols) and theoretical (thin lines : SG EOS ; thick lines : NASG EOS) saturation curves for dodecane with coefficients determined in the temperature range $[300-500 \mathrm{~K}]$.

In this figure, it appears that experimental and NASG theoretical curves are merged in the temperature range $[300-500 \mathrm{~K}]$. The SG and NASG theoretical curves are quite similar for all variables except the saturated liquid specific volume now perfectly predicted with the NASG EOS.

Outside the temperature range, deviations between experimental and NASG theoretical results gradually appear. If better accuracy is needed for higher temperatures the associated temperature range should be adjusted. An example is given hereafter.

For $T \in[400-600 \mathrm{~K}]$, the coefficients of the NASG parameters are re-computed with the method described in Section 4 and are given in the Table III.

The SG coefficients in the same temperature range are given in the Table IV for comparison. 


\begin{tabular}{|l|c|c|}
\hline Coefficients & Liquid phase & Vapor phase \\
\hline$C_{P}(\mathrm{~J} / \mathrm{kg} / \mathrm{K})$ & 3055 & 2322 \\
\hline$C_{v}(\mathrm{~J} / \mathrm{kg} / \mathrm{K})$ & 2532 & 2274 \\
\hline$\gamma$ & 1.21 & 1.02 \\
\hline$P_{\infty}(\mathrm{Pa})$ & $1681 \times 10^{5}$ & 0 \\
\hline$b\left(\mathrm{~m}^{3} / \mathrm{kg}\right)$ & $1.8 \times 10^{-4}$ & 0 \\
\hline$q(\mathrm{~J} / \mathrm{kg})$ & -996054 & -384592 \\
\hline$q^{\prime}(\mathrm{J} /(\mathrm{kg} . \mathrm{K}))$ & 0 & -4301 \\
\hline
\end{tabular}

TABLE III. NASG coefficients for dodecane in the temperature range $[400-600 \mathrm{~K}]$.

\begin{tabular}{|l|c|c|}
\hline Coefficients & Liquid phase & Vapor phase \\
\hline$C_{P}(\mathrm{~J} / \mathrm{kg} / \mathrm{K})$ & 3056 & 2322 \\
\hline$C_{v}(\mathrm{~J} / \mathrm{kg} / \mathrm{K})$ & 2430 & 2274 \\
\hline$\gamma$ & 1.26 & 1.02 \\
\hline$P_{\infty}(\mathrm{Pa})$ & $1804 \times 10^{5}$ & 0 \\
\hline$q(\mathrm{~J} / \mathrm{kg})$ & -996336 & -384592 \\
\hline$q^{\prime}(\mathrm{J} /(\mathrm{kg} . \mathrm{K}))$ & 0 & -6280 \\
\hline
\end{tabular}

TABLE IV. SG coefficients for dodecane in the temperature range $[400-600 \mathrm{~K}]$.

Experimental and theoretical saturation curves are compared in Fig.5. The theoretical saturation curves are represented for both NASG and SG EOS with coefficients of Tables III and IV.

It appears that experimental and NASG theoretical curves are in very good agreement in the temperature range $[400-600 \mathrm{~K}]$. For this particular temperature range the $\mathrm{SG}$ and NASG theoretical curves are almost similar for all variables including the saturated liquid specific volume. Nevertheless this is not the case for arbitrary temperature ranges as shown before.

The method described in this paper may be used to arbitrary liquid and vapor phases. In 

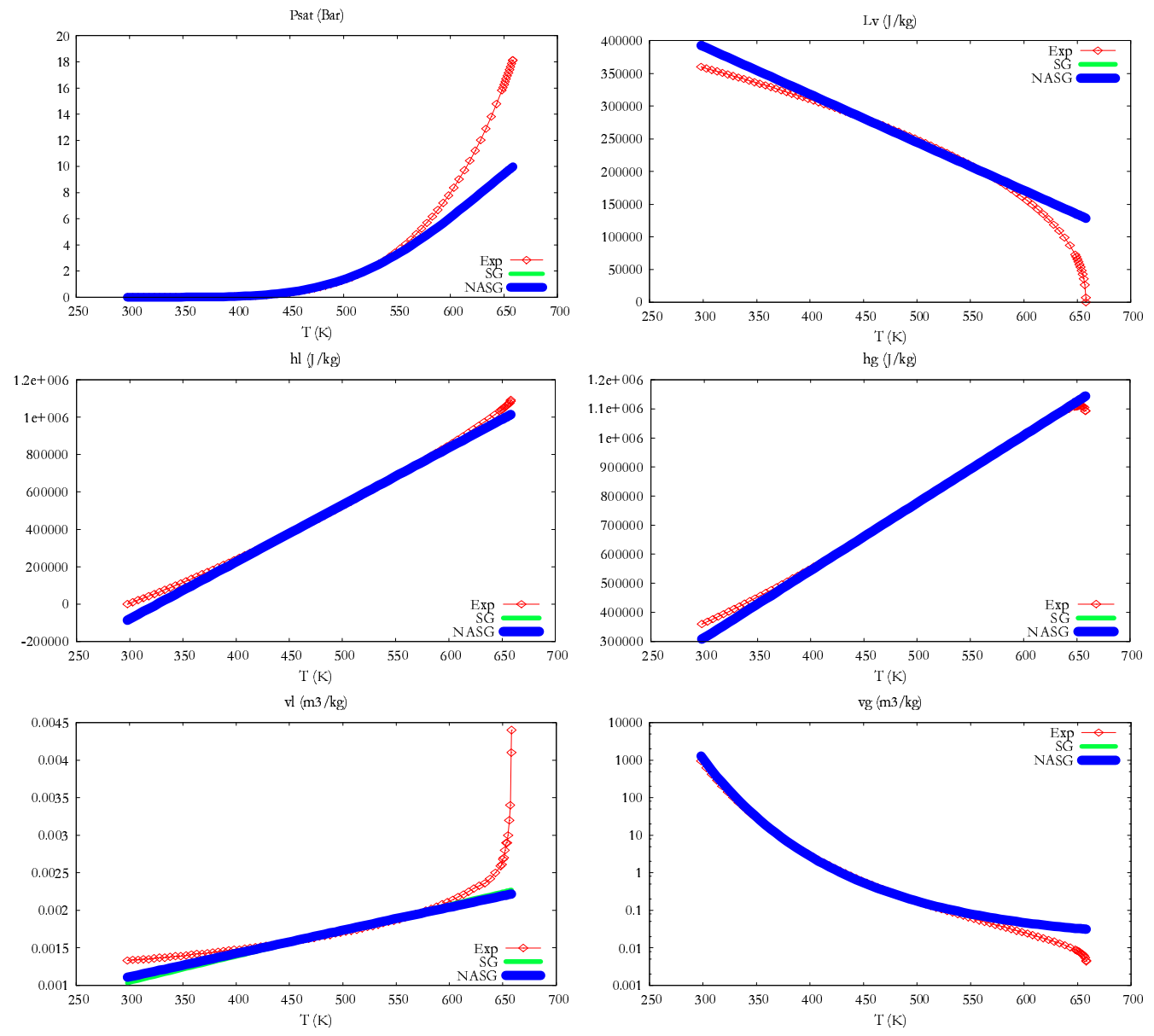

FIG. 5. Comparison between experimental (symbols) and theoretical (thin lines : SG EOS ; thick lines: NASG EOS) saturation curves for dodecane with coefficients determined in the temperature range $[400-600 \mathrm{~K}]$.

the following this method is applied to two extra liquid/vapor couples : liquid water/steam and liquid/vapor oxygen. 


\section{NASG coefficients for liquid water and steam}

The associated experimental curves may be found in [28] for example. The reference state of the liquid phase is given by : $\rho_{0}=957.74 \mathrm{~kg} / \mathrm{m}^{3}, P_{0}=1.0453 \mathrm{bar}, c_{0}=1542 \mathrm{~m} / \mathrm{s}$.

For $T \in[300-500 \mathrm{~K}]$, the corresponding values of the NASG parameters are given in the Table V.

\begin{tabular}{|l|c|c|}
\hline Coefficients & Liquid phase & Vapor phase \\
\hline$C_{P}(\mathrm{~J} / \mathrm{kg} / \mathrm{K})$ & 4285 & 1401 \\
\hline$C_{v}(\mathrm{~J} / \mathrm{kg} / \mathrm{K})$ & 3610 & 955 \\
\hline$\gamma$ & 1.19 & 1.47 \\
\hline$P_{\infty}(\mathrm{Pa})$ & $7028 \times 10^{5}$ & 0 \\
\hline$b\left(\mathrm{~m}^{3} / \mathrm{kg}\right)$ & $6.61 \times 10^{-4}$ & 0 \\
\hline$q(\mathrm{~J} / \mathrm{kg})$ & -1177788 & 2077616 \\
\hline$q^{\prime}(\mathrm{J} /(\mathrm{kg} . \mathrm{K}))$ & 0 & 14317 \\
\hline
\end{tabular}

TABLE V. NASG coefficients for liquid water and steam in the temperature range $[300-500 \mathrm{~K}]$.

The experimental and NASG corresponding curves are shown in Fig.6.

Very good agreement appears between experimental and NASG theoretical curves inside the temperature range $[300-500 \mathrm{~K}]$.

For $T \in[350-550 \mathrm{~K}]$, the computed values of the NASG parameters are given in the Table VI. Experimental and NASG corresponding curves are shown in Fig.7.

In this figure, the correct behavior of the NASG theoretical curves compared to the experimental ones is still noticeable in the temperature range $[350-550 \mathrm{~K}]$. 

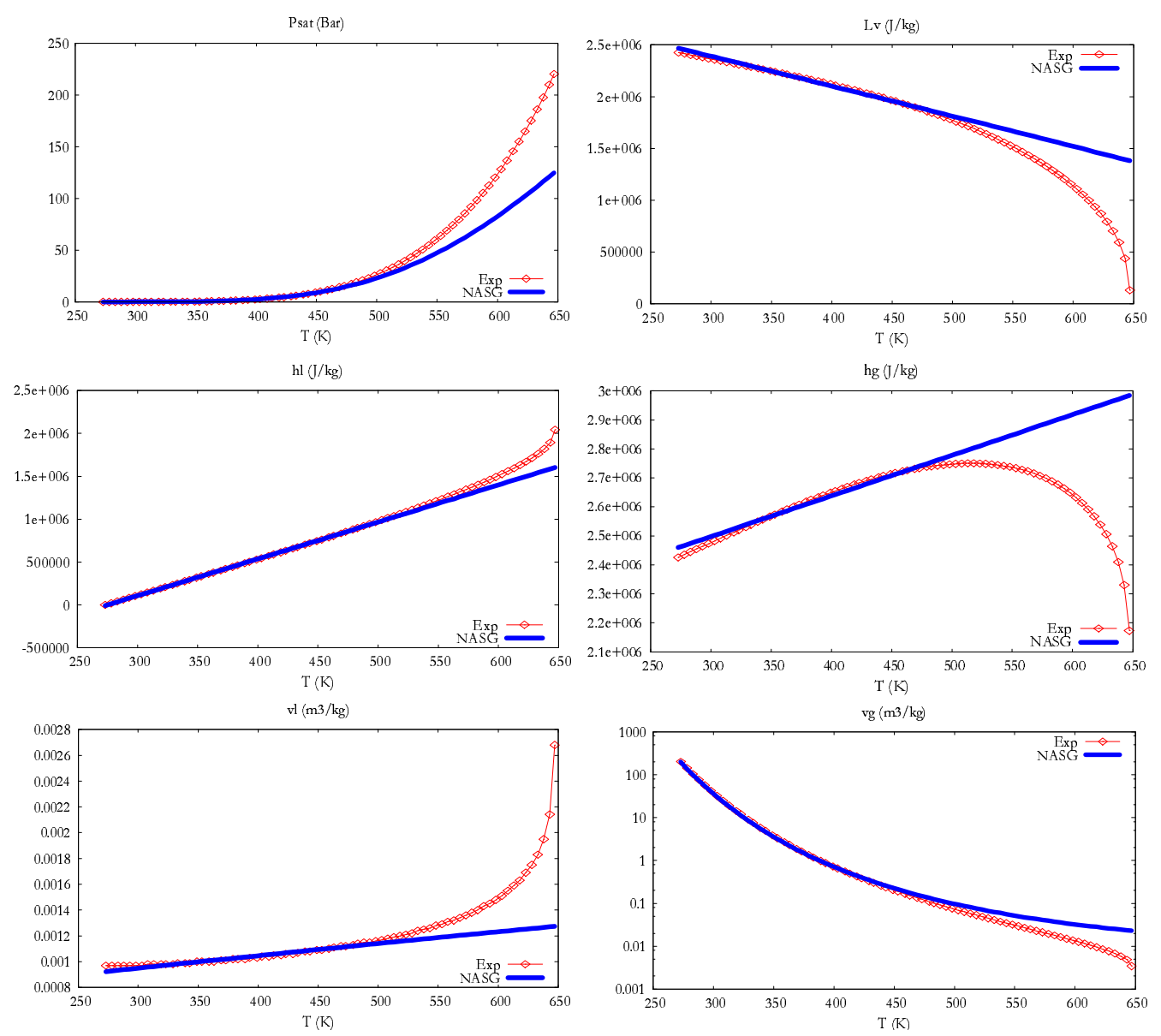

FIG. 6. Comparison between experimental (symbols) and NASG theoretical (lines) saturation curves for liquid water and steam with coefficients determined in the temperature range [300 $500 K]$.

\begin{tabular}{|l|c|c|}
\hline Coefficients & Liquid phase & Vapor phase \\
\hline$C_{P}(\mathrm{~J} / \mathrm{kg} / \mathrm{K})$ & 4444 & 903 \\
\hline$C_{v}(\mathrm{~J} / \mathrm{kg} / \mathrm{K})$ & 3202 & 462 \\
\hline$\gamma$ & 1.39 & 1.95 \\
\hline$P_{\infty}(\mathrm{Pa})$ & $8899 \times 10^{5}$ & 0 \\
\hline$b\left(\mathrm{~m}^{3} / \mathrm{kg}\right)$ & $4.78 \times 10^{-4}$ & 0 \\
\hline$q(\mathrm{~J} / \mathrm{kg})$ & -1244191 & 2287484 \\
\hline$q^{\prime}(\mathrm{J} /(\mathrm{kg} . \mathrm{K}))$ & 0 & 6417 \\
\hline
\end{tabular}

TABLE VI. NASG coefficients for liquid water and steam in the temperature range $[350-550 \mathrm{~K}]$. 

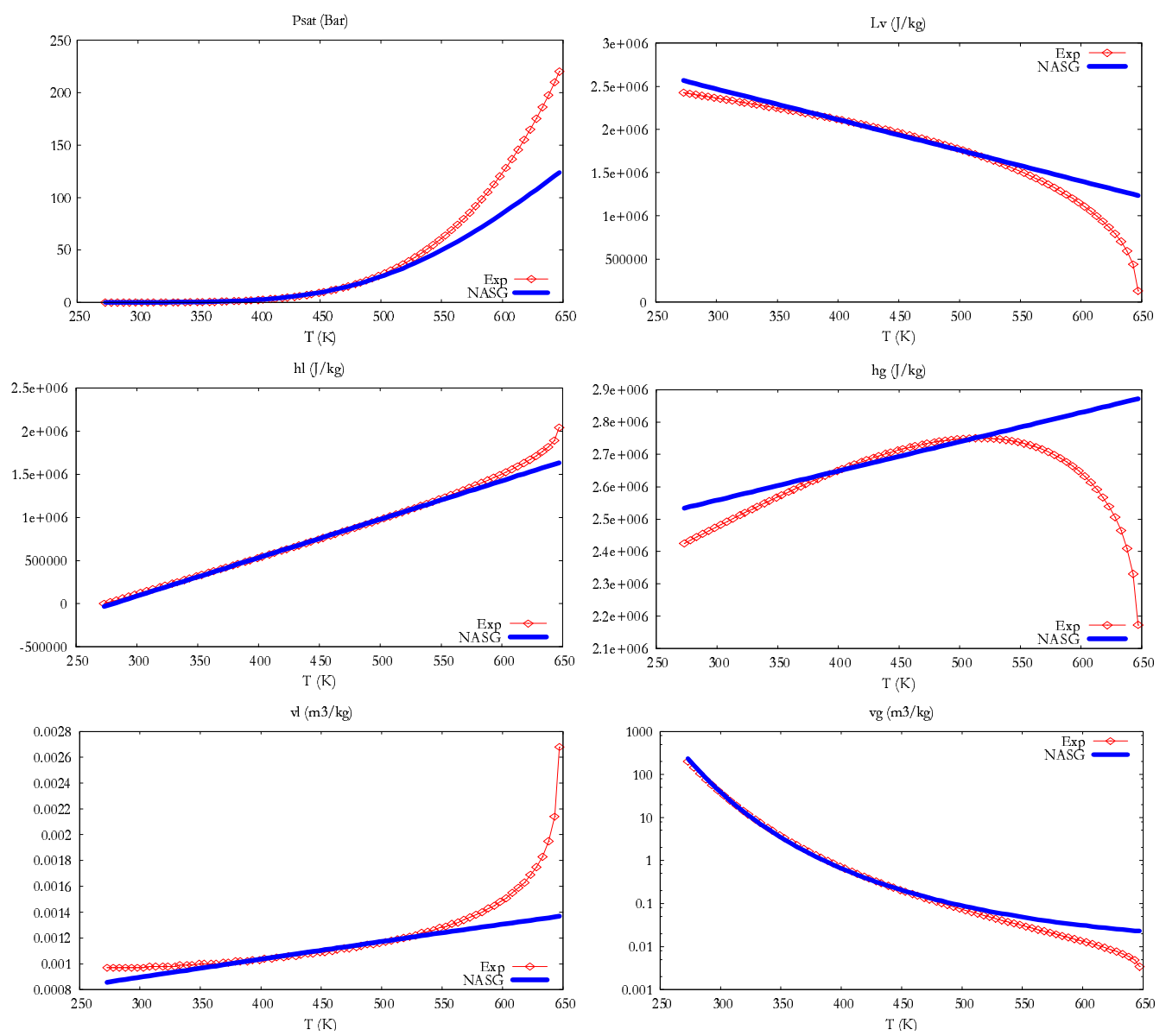

FIG. 7. Comparison between experimental (symbols) and NASG theoretical (lines) saturation curves for liquid water and steam with coefficients determined in the temperature range [350 $550 \mathrm{~K}]$. 


\section{NASG coefficients for liquid and vapor oxygen}

The experimental data for oxygen are available at the NIST website [29]. The liquid reference state data are : $\rho_{0}=1142.1 \mathrm{~kg} / \mathrm{m}^{3}, P_{0}=0.9935 \mathrm{bar}, c_{0}=905.9 \mathrm{~m} / \mathrm{s}$. For $T \in[60-100 \mathrm{~K}]$, the corresponding NASG parameters are given in the Table VII.

\begin{tabular}{|l|c|c|}
\hline Coefficients & Liquid phase & Vapor phase \\
\hline$C_{P}(\mathrm{~J} / \mathrm{kg} / \mathrm{K})$ & 1683 & 791 \\
\hline$C_{v}(\mathrm{~J} / \mathrm{kg} / \mathrm{K})$ & 1016 & 553 \\
\hline$\gamma$ & 1.66 & 1.43 \\
\hline$P_{\infty}(\mathrm{Pa})$ & $1964 \times 10^{5}$ & 0 \\
\hline$b\left(\mathrm{~m}^{3} / \mathrm{kg}\right)$ & $5.71 \times 10^{-4}$ & 0 \\
\hline$q(\mathrm{~J} / \mathrm{kg})$ & -284969 & 7632 \\
\hline$q^{\prime}(\mathrm{J} /(\mathrm{kg} . \mathrm{K}))$ & 0 & -3601 \\
\hline
\end{tabular}

TABLE VII. NASG coefficients for oxygen in the temperature range [60 - $100 \mathrm{~K}]$.

The associated curves are represented in Fig. 8 showing excellent agreement in the corresponding temperature range.

For another temperature range $[80-120 \mathrm{~K}]$, the values of the NASG parameters are given in the Table VIII.

\begin{tabular}{|l|c|c|}
\hline Coefficients & Liquid phase & Vapor phase \\
\hline$C_{P}(\mathrm{~J} / \mathrm{kg} / \mathrm{K})$ & 1741 & 552 \\
\hline$C_{v}(\mathrm{~J} / \mathrm{kg} / \mathrm{K})$ & 791 & 299 \\
\hline$\gamma$ & 2.2 & 1.85 \\
\hline$P_{\infty}(\mathrm{Pa})$ & $2036 \times 10^{5}$ & 0 \\
\hline$b\left(\mathrm{~m}^{3} / \mathrm{kg}\right)$ & $4.57 \times 10^{-4}$ & 0 \\
\hline$q(\mathrm{~J} / \mathrm{kg})$ & -290222 & 29274 \\
\hline$q^{\prime}(\mathrm{J} /(\mathrm{kg} . \mathrm{K}))$ & 0 & -7527 \\
\hline
\end{tabular}

TABLE VIII. NASG coefficients for oxygen determined in the temperature range $[80-120 \mathrm{~K}]$.

The associated curves are represented in Fig.9. 

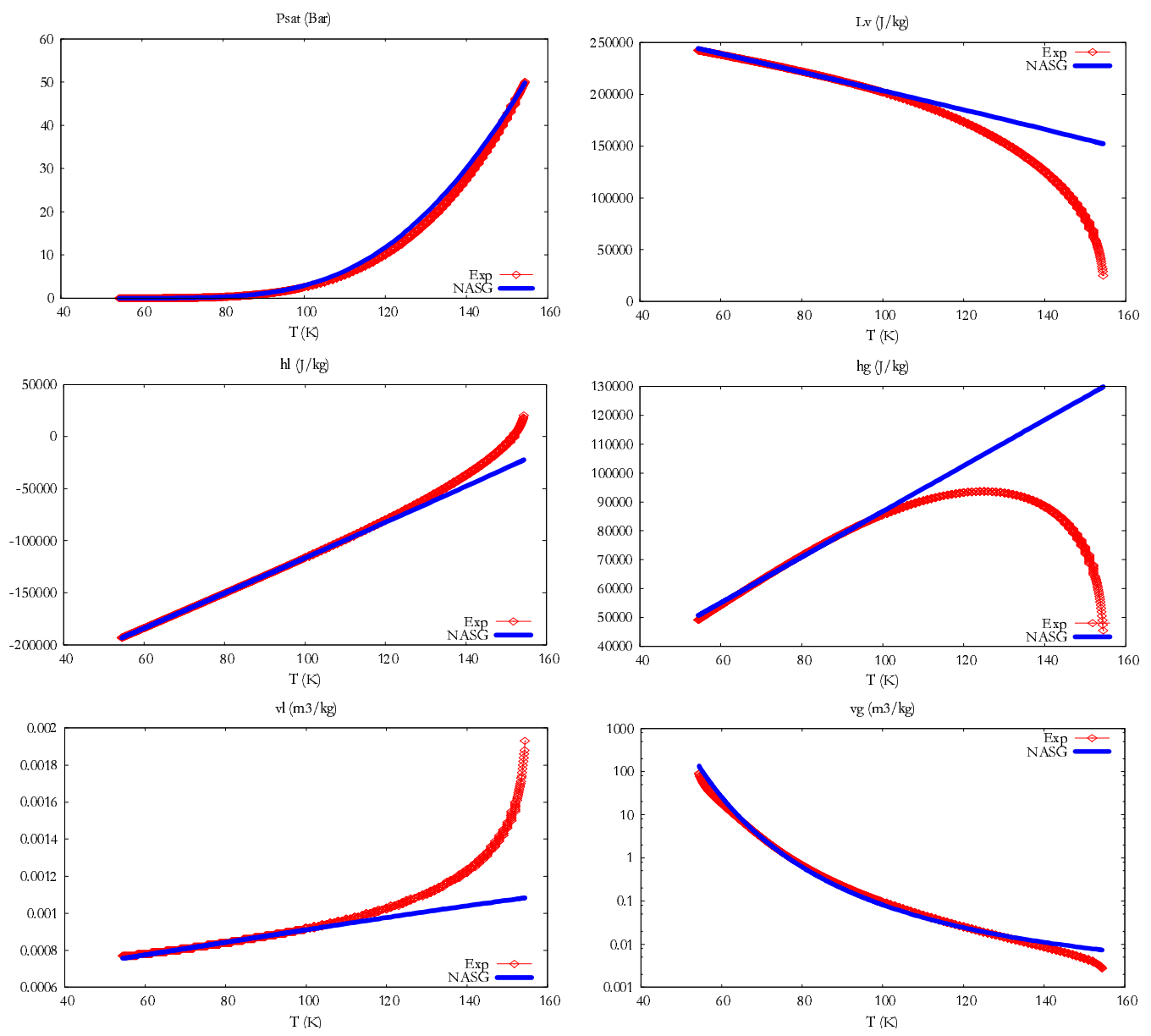

FIG. 8. Comparison between experimental (symbols) and NASG theoretical (lines) saturation curves for oxygen with coefficients determined in the temperature range $[60-100 \mathrm{~K}]$.

For any temperature range considered above the experimental and NASG theoretical curves are in very good agreement in the related temperature range.

In the following section comparison with van der Waals constants is addressed. 

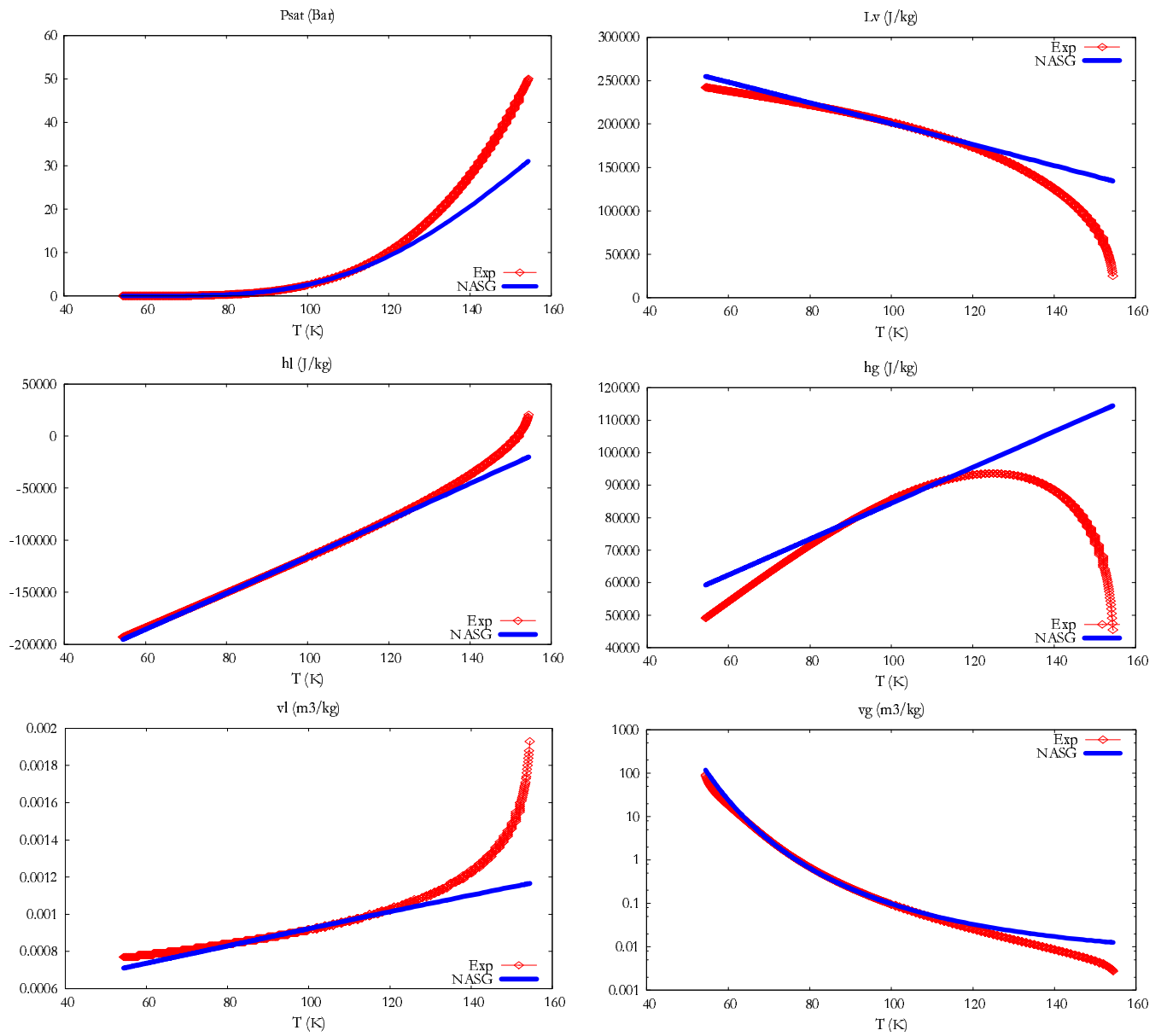

FIG. 9. Comparison between experimental (symbols) and NASG theoretical (lines) saturation curves for oxygen with coefficients determined in the temperature range $[80-120 \mathrm{~K}]$. 


\section{COMPARISON WITH VAN DER WAALS CONSTANTS}

It is interesting to compare the constants of the NASG EOS with those of the van der Waals one. Indeed, in the NASG formulation attractive effects are constant and summarized in the term $\gamma P_{\infty}$ while in van der Waals EOS they are varying with the specific volume. From this evidence an important difference appears : NASG EOS is convex while van der Waals EOS is not. However physically speaking the various constants should be closed each others. To do this, the van der Waals EOS has to be expressed in the same system of units. In the literature it is found in molar units,

$$
P(V, T)=\frac{n \hat{R} T}{V-n \beta}-\frac{n^{2} \alpha}{V^{2}}
$$

where $n$ represents the number of moles and $\hat{R}=8.314 \mathrm{~J} /(\mathrm{mol} . K)$ is the molar gas constant. The constants $\alpha$ and $\beta$ are expressed in the same system i.e. $\left(J . m^{3}\right) / m^{2} l^{2}$ and $m^{3} / m o l$ respectively.

In mass units relation (73) becomes,

$$
P(V, T)=\frac{n \hat{M} \frac{\hat{R}}{\hat{M}} T}{V\left(1-\frac{n \hat{M} \beta}{V \hat{M}}\right)}-\frac{(n \hat{M})^{2} \alpha}{V^{2} \hat{M}^{2}},
$$

where $\hat{M}$ represents the molar mass.

In terms of specific volume relation (74) reads,

$$
P(v, T)=\frac{R T}{\left(v-\frac{\beta}{\hat{M}}\right)}-\frac{\alpha}{v^{2} \hat{M}^{2}},
$$

where $R=\frac{\hat{R}}{\hat{M}}$ is the gas constant in mass unit.

Equation (75) has to be compared with the NASG EOS expressed as,

$$
P(v, T)=\frac{(\gamma-1) C_{v} T}{v-b}-P_{\infty} .
$$

Therefore the constant $b$ has to be compared to $\frac{\beta}{\hat{M}}$ and $P_{\infty}$ has to be compared to $\frac{\alpha}{v^{2} \hat{M}^{2}}=$ $\frac{\rho^{2} \alpha}{\hat{M}^{2}}$. For the last coefficients comparison is achieved in the reference state 0 used to determine the NASG EOS parameters. Two fluids are considered in the following for comparison 
: water and oxygen.

For water, the van der Waals parameters are : $\alpha=0.553\left(\mathrm{~J}^{3} \mathrm{~m}^{3}\right) / \mathrm{mol}^{2}, \beta=3.05 \times$ $10^{-5} \mathrm{~m}^{3} / \mathrm{mol}$ and $\hat{M}=18 \times 10^{-3} \mathrm{~kg} / \mathrm{mol}$. The density of the reference state 0 is : $\rho_{0}=957.74 \mathrm{~kg} / \mathrm{m}^{3}$.

The coefficients to compare are shown in the Table IX.

\begin{tabular}{|c|c|}
\hline van der Waals coefficients & NASG coefficients \\
\hline$\frac{\rho_{0}^{2} \alpha}{\hat{M}^{2}}=15655 \times 10^{5} \mathrm{~Pa}$ & $P_{\infty}=[7028,8899] \times 10^{5} \mathrm{~Pa}$ \\
\hline$\frac{\beta}{\hat{M}}=16.9 \times 10^{-4} \mathrm{~m}^{3} / \mathrm{kg}$ & $b=[4.78,6.61] \times 10^{-4} \mathrm{~m}^{3} / \mathrm{kg}$ \\
\hline
\end{tabular}

TABLE IX. Comparison between van der Waals and NASG coefficients for water.

For oxygen, the van der Waals parameters are given by : $\alpha=0.138\left(\mathrm{~J} \cdot \mathrm{m}^{3}\right) / \mathrm{mol}^{2}, \beta=$ $3.186 \times 10^{-5} \mathrm{~m}^{3} / \mathrm{mol}$ and $\hat{M}=32 \times 10^{-3} \mathrm{~kg} / \mathrm{mol}$. The density of the reference state 0 is $\rho_{0}=1142.1 \mathrm{~kg} / \mathrm{m}^{3}$.

The coefficients to compare are shown in the Table $\mathrm{X}$ for oxygen.

\begin{tabular}{|c|c|}
\hline van der Waals coefficients & NASG coefficients \\
\hline$\frac{\rho_{0}^{2} \alpha}{\hat{M}^{2}}=1758 \times 10^{5} \mathrm{~Pa}$ & $P_{\infty}=[1964,2036] \times 10^{5} \mathrm{~Pa}$ \\
\hline$\frac{\beta}{\hat{M}}=9.96 \times 10^{-4} \mathrm{~m}^{3} / \mathrm{kg}$ & $b=[4.57,5.71] \times 10^{-4} \mathrm{~m}^{3} / \mathrm{kg}$ \\
\hline
\end{tabular}

TABLE X. Comparison between van der Waals and NASG coefficients for oxygen.

It is remarkable to note that the order of magnitude of $\frac{\rho^{2} \alpha}{\hat{M}^{2}}$ and $P_{\infty}$ are the same for both oxygen and water. The same remark holds for the covolumes $\frac{\beta}{\hat{M}}$ and $b$. This is a remarkable fact as the van der Waals parameters are determined from molecular physics while NASG parameters are just consequences of the saturation curves. Also, there is no reason that van der Waals parameters and NASG ones be strictly equal as the attractive potential $\frac{\rho^{2} \alpha}{\hat{M}^{2}}$ in the van der Waals EOS varies with density, while it is constant in NASG EOS.

\section{CONCLUSION}

A novel equation of state (NASG EOS) has been built to deal with liquid and vapor phases. A method to determine EOS parameters is also given. The coefficients of both 
phases are strongly linked and are obtained to fit the experimental saturation curves of the liquid/vapor couple. In particular the NASG formulation allows to cure the liquid specific volume inaccuracy present in the SG formulation [17]. The method described in the paper to compute liquid and vapor NASG EOS parameters has been applied to three different liquid/vapor couples : dodecane, water and oxygen. The corresponding theoretical and experimental curves are in good agreement for various temperature ranges and for all liquid/vapor couples considered herein.

With the NASG EOS there is no difficulty to derive exact and approximate Riemann solvers for various flow models $[24,30,31]$. Boundary conditions can be treated accurately as characteristic relations and Riemann invariants are easy to determine. Various relaxation solvers such as those given in [32] can also be derived unambiguously.

\section{APPENDIX: CONVEXITY OF THE NASG EOS}

Convexity of the NASG EOS is examined in this part. For this the state function $e(v, s)$ is needed.

First relation (35) is used to express $T$ as a function of pressure $P$ and specific volume $v$,

$$
T(P, v)=\frac{\left(P+P_{\infty}\right)(v-b)}{(\gamma-1) C_{v}} .
$$

Combining relations (77) and (31) leads to a relation linking pressure $P$, specific volume $v$ and specific entropy $s$,

$$
P(v, s)=\left(\frac{(\gamma-1) C_{v}}{v-b}\right)^{\gamma} \exp \left(\frac{s-q^{\prime}}{C_{v}}\right)-P_{\infty} .
$$

Then the state function $e(v, s)$ is obtained embedding relation (78) in (34),

$$
e(v, s)=C_{v}\left(\frac{(\gamma-1) C_{v}}{v-b}\right)^{\gamma-1} \exp \left(\frac{s-q^{\prime}}{C_{v}}\right)+P_{\infty}(v-b)+q
$$

The necessary conditions to have a convex EOS are the following,

$$
\left\{\begin{array}{l}
\left.\frac{\partial^{2} e}{\partial s^{2}}\right)_{v} \geq 0 \\
\left.\frac{\partial^{2} e}{\partial v^{2}}\right)_{s} \geq 0 \\
\left.\left.\frac{\partial^{2} e}{\partial s^{2}}\right)_{v} \frac{\partial^{2} e}{\partial v^{2}}\right)_{s}-\left(\frac{\partial^{2} e}{\partial v \partial s}\right)^{2} \geq 0
\end{array}\right.
$$


For the NASG EOS, the second derivatives of specific internal energy given by relation (79) read,

$$
\begin{gathered}
\left.\frac{\partial^{2} e}{\partial s^{2}}\right)_{v}=\frac{1}{C_{v}}\left(\frac{(\gamma-1) C_{v}}{v-b}\right)^{\gamma-1} \exp \left(\frac{s-q^{\prime}}{C_{v}}\right) \\
\left.\frac{\partial^{2} e}{\partial v^{2}}\right)_{s}=\frac{\gamma}{(\gamma-1) C_{v}}\left(\frac{(\gamma-1) C_{v}}{v-b}\right)^{\gamma+1} \exp \left(\frac{s-q^{\prime}}{C_{v}}\right), \\
\frac{\partial^{2} e}{\partial v \partial s}=-\frac{1}{C_{v}}\left(\frac{(\gamma-1) C_{v}}{v-b}\right)^{\gamma} \exp \left(\frac{s-q^{\prime}}{C_{v}}\right) .
\end{gathered}
$$

From relations (81) and (82) it follows that $\left.\frac{\partial^{2} e}{\partial s^{2}}\right)_{v}>0$ and $\left.\frac{\partial^{2} e}{\partial v^{2}}\right)_{s}>0$.

Furthermore the last condition in (80) is fulfilled as,

$$
\left.\left.\frac{\partial^{2} e}{\partial s^{2}}\right)_{v} \frac{\partial^{2} e}{\partial v^{2}}\right)_{s}-\left(\frac{\partial^{2} e}{\partial v \partial s}\right)^{2}=\frac{1}{(\gamma-1) C_{v}^{2}}\left(\frac{(\gamma-1) C_{v}}{v-b}\right)^{2 \gamma} \exp \left(\frac{2\left(s-q^{\prime}\right)}{C_{v}}\right)>0 .
$$

[1] H. Lund, "A hierarchy of relaxation models for two-phase flow", SIAM J. on Applied Mathematics 72, 1713-1741(2012).

[2] S. Le Martelot, R. Saurel, and O. Le Métayer, "Steady one-dimensional nozzle flow solutions of liquid-gas mixtures", J. Fluid Mech. 737, 146-175(2013).

[3] S. Le Martelot, R. Saurel, and B. Nkonga, "Towards the direct numerical simulation of nucleate boiling flows", Int. J. Multiphase Flow 66, 62-78(2014).

[4] G. Allaire, S. Clerc, and S. Kokh, "A five-equation model for the simulation of interfaces between compressible fluids", J. Comput. Phys. 181, 577-616(2002).

[5] A.K. Kapila, R. Menikoff, J.B. Bdzil, S.F. Son, and D.S. Stewart, "Two-phase modeling of deflagration-to-detonation transition in granular materials : reduced equations", Phys. Fluids 13, 3002-3024(2001).

[6] A. Murrone, and H. Guillard, "A five equation reduced model for compressible two phase flow problems", J. Comput. Physics 202, 664698(2005).

[7] R. Saurel, F. Petitpas, and R. Abgrall, "Modelling phase transition in metastable liquids : application to cavitating and flashing flows", J. Fluid Mech. 607, 313-350(2008).

[8] R. Saurel, F. Petitpas, and R.A. Berry, "Simple and efficient relaxation methods for interfaces separating compressible fluids, cavitating flows and shocks in multiphase mixtures", J. Comput. Physics 228, 1678-1712(2009). 
[9] R. Abgrall, and R. Saurel, "Discrete equations for physical and numerical compressible multiphase mixtures", J. Comput. Phys. 186, 361-396(2003).

[10] M.R. Baer, and J.W. Nunziato, "A two-phase mixture theory for the deflagration-todetonation transition (DDT) in reactive granular materials", Int. J. Multiphase Flow 12, 861-889(1986).

[11] J.B. Bdzil, R. Menikoff, S.F. Son, A.K. Kapila, and D.S. Stewart, "Two-phase modeling of deflagration-to-detonation transition in granular materials : a critical examination of modeling issues", Phys. Fluids 11, 378-402(1999).

[12] A. Chinnayya, E. Daniel, and R. Saurel, "Modelling detonation waves in heterogeneous energetic materials", J. Comp. Physics 196, 490-538(2004).

[13] A.K. Kapila, S.F. Son, J.B. Bdzil, R. Menikoff, and D.S. Stewart, "Two-phase modeling of DDT : structure of the velocity-relaxation zone", Phys. Fluids 9, 3885-3897(1997).

[14] O. Le Métayer, J. Massoni, and R. Saurel, "Modelling evaporation fronts with reactive Riemann solvers", J. Comput. Phys. 205, 567-610(2005).

[15] R. Saurel, S. Gavrilyuk, and F. Renaud, "A multiphase model with internal degrees of freedom : application to shock-bubble interaction", J. Fluid Mech. 495, 283-321(2003).

[16] R. Saurel, and O. LeMetayer, "A multiphase model for compressible flows with interfaces, shocks, detonation waves and cavitation", J. Fluid Mech. 431, 239-271(2001).

[17] O. Le Métayer, J. Massoni, and R. Saurel, "Elaborating equations of state of a liquid and its vapor for two-phase flow models", Int. J. Thermal Sciences 43, 265-276(2004).

[18] R.C. Reid, J.M. Prausnitz, and B.E. Poling, "The properties of gases and liquids", $4^{\text {th }}$ edition, Mc Graw-Hill(1987).

[19] A.A. Frost, and D.R. Kalkwarf, "A semi-empirical equation for the vapor pressure of liquids as a function of temperature", J. Chem. Phys. 21, 264-267(1953).

[20] J.R. Simões-Moreira, "Adiabatic evaporation waves", Ph.D.thesis, Rensselaer Polytechnic Institute, Troy, New-York(1994).

[21] D. Furfaro, and R. Saurel, "Modeling droplet phase change in the presence of a multicomponent gas mixture", Applied Mathematics and Computation, 272(2), 518-541(2016).

[22] S.K. Godunov, A.V. Zabrodin, M.I. Ivanov, A.N. Kraiko, and G.P. Prokopov, "Numerical solution of multidimensional problems of gas dynamics". Moscow Izdatel Nauka, 1(1976). 
[23] F. Harlow, and A. Amsden, "Fluid dynamics", Monograph LA-4700, Los Alamos National Laboratory, Los Alamos, NM(1971).

[24] R. Menikoff, and B.J. Plohr, "The Riemann problem for fluid flow of real materials", Rev. Mod. Phys. 61, 75-130(1989).

[25] G.A. Hirn, "Exposition analytique et expérimentale de la théorie mécanique de la chaleur", communication(1862), in French.

[26] A. Brin, "Contribution à l'étude de la couche capillaire et de la pression osmotique". Thèse d'Etat, Faculté des Sciences de l'Université de Paris(1956),in French.

[27] J.P. Perez, and A. Romulus, "Thermodynamique: fondements et applications", Masson(1993),in French.

[28] R. Oldenbourg, "Properties of water and steam in SI-units", Springer-Verlag Berlin Heidelberg, New-York(1989).

[29] http://webbook.nist.gov/chemistry/fluid/

[30] J.P. Cocchi, and R. Saurel, "A Riemann problem based method for the resolution of compressible multimaterial flows", J. Comput. Phys. 137, 265-298(1997).

[31] B.J. Plohr, "Shockless acceleration of thin plates modeled by a tracked random choice method", AIAA J. 26, 470-478(1988).

[32] O. Le Métayer, J. Massoni, and R. Saurel, "Dynamic relaxation processes in compressible multiphase flows. Application to evaporation phenomena", ESAIM Proceedings 40, 103-123(2013). 